\title{
Empirical Study on Logistics and Regional Economic Development in Zhengzhou
}

\author{
XUE Ke $\mathrm{Ke}^{1, \mathrm{a}}$ \\ ${ }^{1}$ School of Logistics \& E-business, Henan University of Animal Husbandry \& Economy, \\ Zhengzhou, China \\ axzxhxk@qq.com
}

Keywords: Regional economy; logistics development; Zhengzhou City

\begin{abstract}
Logistics as a basic industry of the regional economy, the development of logistics can greatly promote the high-quality development of the economy. Based on the data of Zhengzhou City's 2010-2018 statistical bulletin, the gray correlation analysis method is used to analyze the relationship between Zhengzhou logistics and regional economic development, to clarify the relationship between logistics and gross national product and various industries, The direction forms a positive trend of mutual support and promotion between the logistics industry and the regional economy.
\end{abstract}

\section{郑州市物流与区域经济发展关系实证分析 \\ 薛珂 ${ }^{1, a}$ \\ 1河南牧业经济学院物流与电商学院, 郑州, 河南, 中国 \\ axzxhxk@qq.com}

关键词：区域经济；物流发展；郑州市

中文摘要. 物流作为区域经济的基础性产业, 物流的发展可以极大的促进经济的高质量发展。 基于郑州市2010-2018年统计公报数据，运用灰色关联分析法分析郑州市物流与区域经济发展 的关系，明确物流与国民生产总值、各产业之间的关系，形成物流业与区域经济相互支持和 促进的积极态势。

\section{1. 引言}

作为“一带一路”倡议重要实施节点、中原城市群中心城市，郑州是支撑中部地区崛起的 重要力量, 作为新一线城市, 郑州的经济发展在不断腾飞。同时, 作为第一批国家物流枢纽 城市，近年来郑州市的物流业在不断发展，2017年《郑州市人民政府加快现代物流业转型发 展的实施意见》、《郑州市人民政府加快建设现代国际物流中心的实施意见》等政策不断出 台，极大的带动了郑州物流业的提速。区域经济与区域物流有着复杂而密切的联系，物流是 区域经济的基础性产业, 而区域经济的发展又离不开物流 ${ }^{[1]}$, 两者之间相互影响, 协同发展。 谭清美等 ${ }^{[2]}$ 较早的研究了物流能力对区域经济的贡献度;刘南等 ${ }^{[3]}$ 运用格兰杰因果检验方法论 证了现代物流发展与经济增长之间的双向因果关系; 郭湖滨 ${ }^{[4]}$ 则利用耦合协调发展的作用机理 探究了长江经济带的区域经济与物流之间的关系。所以, 以郑州为例研究物流与区域经济之 间的关系，能够为郑州市物流业的进一步发展指明方向，同时对促进郑州产业转型升级有着 重要的借鉴意义。 


\section{2. 郑州市物流业与区域经济发展现状}

\section{1 郑州市物流业发展现状}

郑州是国际性综合交通枢纽城市、全国物流中心节点城市、全国一级物流园区布局城市、 全国第二批城市共同配送试点城市、全国物流枢纽城市，随着供给侧结构性改革和降本增效 的持续推进, 郑州市物流业需求稳定增长, 物流业规模进一步扩大, 运势整体稳中趋好。2018 年, 全市社会物流总额达到 23604.53 亿元, 同比增长 $10.3 \%$; 物流业增加值 787.75 亿元, 增长 $10.4 \%$ ，占服务业增加值的 $14.2 \%$ ，占GDP的 $7.8 \%$; 社会物流总费用 1493.96 亿元，增长 $8.8 \%$ ， 与GDP的比率为 $14.7 \%$; 物流业总收入 1314.49 亿元, 增长 $12.8 \%$; 货物运输量 2.76 亿吨, 货物 周转量 864.36 亿吨公里, 分别增长 $15.8 \%$ 和 $10.1 \%$; 郑州机场货邮吞吐量 51.49 万吨, 增长 $2.4 \%$; 全市快递业务量 68246.34 万件，业务收入 74.9 亿元，分别增长 $38.88 \%$ 和 $29.89 \%$ 。中欧班列（郑 州）合计开行752班; 进出口总额完成 4105 亿元，比上年增长 $2.2 \%$; 郑州海关共监管跨境电商 进出口清单 9507.3 万票。本土物流企业不断发展壮大，传统运输、仓储、流通物流企业加快 向现代物流企业转型, 截止2018年底郑州市共评出A级物流企业87家，其中5A级物流企业8 家，4A级物流企业36家，3A级物流企业38家，2A级物流企业5家。郑州市物流运行环境不断 优化，出台了一系列支持物流业发展的政策，并初步形成了“2+9”立体化口岸开放体系，通关 效率位居全国前列, 并建立了中欧国际多式联运综合服务信息平台和国内唯一一家以机场枢 纽为中心的国际物流多式联运数据交易服务平台, 物流运行成本呈现回落趋势, 物流效率显 著改善。

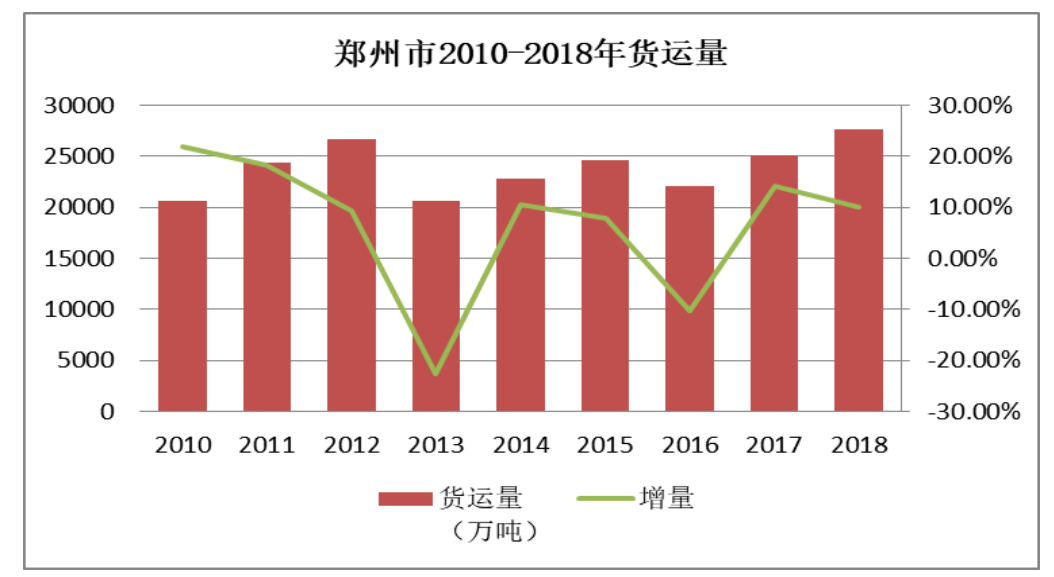

数据来源 郑州市统计局年度数据

图1 郑州市2010-2018年货运量

\section{2 郑州市区域经济发展现状}

郑州市积极发挥区位优势, 经济规模稳定增长, 产业结构不断优化。2018 年地区生产总 值达 10143.3 亿元, 首次进入万亿俱乐部, 同比增长 $8.1 \%$, 占全省比重达 $21.1 \%$ 、占中原城市 群比重达 $14 \%$ 。其中, 第一产业增加值 147.1 亿元, 增长 $2.1 \%$; 第二产业增加值 4450.7 亿元, 增长 $8.1 \%$; 第三产业增加值 5545.5 亿元，增长 $8.3 \%$; ; 第二、三产业增加值均高于全国 $35.8 \%$ 、 7.6\%的平均增速。工业七大主导产业对全市工业增长的贡献率为 $93.9 \%$ ，已形成电子信息、 汽车及装备制造等多个5000亿级产业集群。三产比例为1.4:43.9:54.7, 服务业占比持续提升, 产业结构不断优化。作为国家中心城市, 郑州区域带动作用凸显, 内陆地区对外开放门户已 初步形成, 发展潜力巨大。

综上所述，郑州市物流与区域经济发展势态良好，相互之间关系密切。而通常来说，区 域经济发展程度和规模, 对物流的发展起着决定性的作用, 因此需进一步探讨郑州物流与区 域经济之间的关系，对郑州物流的进一步发展有针对性的提出可行意见。 


\section{3. 郑州市物流业与区域经济发展关系模型构建}

\section{1 指标选取}

在进行物流业与区域经济发展关系研究时, 指标的选取非常重要。根据阅读文献, 并在 考虑数据可得性和可靠性的基础上，采用以下指标开展实际模型构建。

\section{1 .1 物流业指标选取}

对于物流业常见的统计指标有货运量和货物周转量。其中货物周转量等于货运量乘以运 输距离, 在一定程度上反映着地区物流业发展规模, 因此选取该值为衡量郑州市物流业发展 的指标值。

\subsection{2 区域经济指标选取}

国民生产总值（GDP）是研究地区经济发展的常用指标，同时，为了更深入的了解物流 业对区域经济中三种产业的关系，选取了第一、第二、第三产业的产值进行进一步对比，挖 掘郑州地区对物流业影响较深的产业。

\section{2 数据来源}

以上选取的指标均可以从郑州市统计公报中获取, 主要数据从郑州市统计局年度数据中 获取, 选取了2010年-2018年中9年的统计数据作为样本值, 具体数据如表1所示:

表1＼cjkstart郑州市物流业与区域经济主要指标

\begin{tabular}{|c|c|c|c|c|c|}
\hline 年份 & $\begin{array}{c}\text { 货运周转量 } \\
\text { (亿吨公里) }\end{array}$ & $\begin{array}{c}\text { 生产总值 } \\
\text { (亿元) }\end{array}$ & $\begin{array}{c}\text { 第一产业 } \\
\text { (亿元) }\end{array}$ & $\begin{array}{c}\text { 第二产业 } \\
\text { (亿元) }\end{array}$ & $\begin{array}{c}\text { 第三产业 } \\
\text { (亿元) }\end{array}$ \\
\hline 2010 & 479.8 & 4029.3 & 122.8 & 2197.4 & 1709.1 \\
\hline 2011 & 564.1 & 4954.1 & 129.8 & 2735.7 & 2088.5 \\
\hline 2012 & 630.9 & 5517.1 & 140.5 & 2933.1 & 2443.6 \\
\hline 2013 & 527.7 & 6197.4 & 144.9 & 3228.6 & 2823.9 \\
\hline 2014 & 537 & 6777 & 147.1 & 3487.1 & 3142.7 \\
\hline 2015 & 548.2 & 7311.5 & 150.9 & 3604.2 & 3556.4 \\
\hline 2016 & 686.4 & 8114 & 156.4 & 3796.9 & 4160.7 \\
\hline 2017 & 779.2 & 9193.8 & 151.6 & 4082.7 & 4959.5 \\
\hline 2018 & 864.4 & 10143.3 & 147.1 & 4450.7 & 5545.5 \\
\hline
\end{tabular}

数据来源 郑州市统计局年度数据

\section{3 模型构建}

为了观察物流业与区域经济及产业发展的相关性，采用灰色关联分析的方法进行观测 ${ }^{[6]}$ 。 灰色关联分析主要是分析在发展过程中, 各子序列与母数列之间的变化趋势是否具有一致性, 若呈现同步变化, 则代表关联性较大; 反之, 关联性较小。关联分析法的主要步骤如下:

\subsection{1 确定比较序列。}

本文主要研究物流业与区域经济的发展关系，因此以货物周转量为母序列，国民生产总 值（GDP）、三产产值为四个子序列。

\subsection{2 无量纲处理。}

因为不同序列的量纲有所不同，为了更好的关注变化趋势，而不被数据之间的差异性干 扰, 需要对数据进行无量纲处理。无量纲处理的方式有很多, 如均值化和初始化等。本文为 年度统计数据，同一序列之间的量级差距不大，通过采用除以序列初值进行归一化处理。

3.3.3 计算关联度系数。

设 $\left\{x^{i}\right\}=\left\{x_{1}^{i}, x_{2}^{i}, \cdots, x_{n}^{i}\right\}$ 为母数列, $\left\{x^{*}\right\}=\left\{x_{1}^{*}, x_{2}^{*}, \cdots, x_{n}^{*}\right\}$ 为需要比较的子数列, 根据灰色关联度理 论，计算关联系数: 


$$
\zeta_{\mathrm{i}}=\frac{\min _{\mathrm{i}} \min _{k}\left|x_{k}^{*}-x_{k}^{i}\right|+\rho \max _{\mathrm{i}} \max _{k}\left|x_{k}^{*}-x_{k}^{i}\right|}{\left|x_{k}^{*}-x_{k}^{i}\right|+\rho \max _{\mathrm{i}} \max _{k}\left|x_{k}^{*}-x_{k}^{i}\right|}
$$

$\rho$ 是一个可调节的系数, 一般取 0.5 。

\subsection{4 计算关联系数均值}

$$
\gamma_{k}(k)=\frac{1}{n} \sum_{k-1}^{n} \zeta_{i}(k)
$$

$\gamma_{k}$ 值越大，则该子序列与母序列的关联性越强。

\section{4 实证分析}

将郑州市物流业与区域经济主要指标数据代入上述模型, 运用初值法进行无量纲处理, 处理后物流业与区域经济及相关产业关系如图 2 所示, 根据公式计算关联度系数, 相关变化 趋势如图 3 所示:

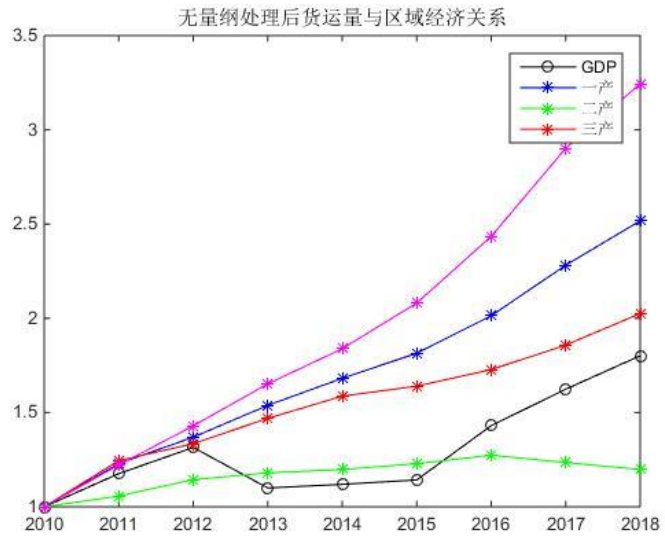

图2 无量纲处理后物流业与区域经济相关指标关系

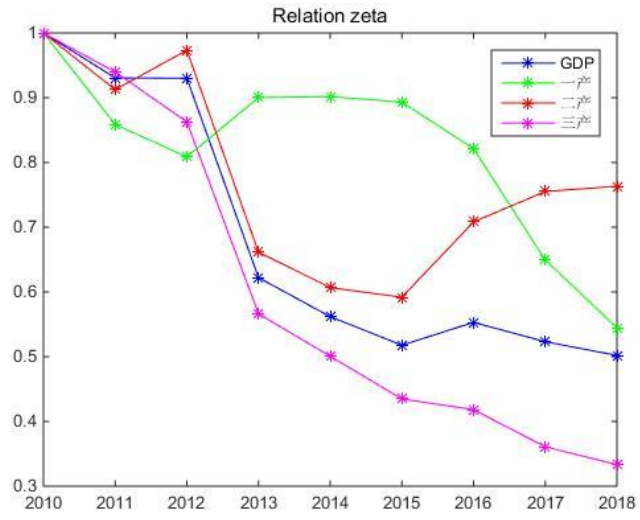

图3 物流业与区域经济各产业关联度系数

计算相关度均值, 最终计算出的灰色关联度矩阵为:

$$
\gamma=[0.6823,0.8197,0.7747,0.6018]
$$

上述指标分别为郑州市国民生产总值（GDP）、三产产值与货物周转量之间的关系，从 数据中可以看出, 所有数据均大于 0.5 , 认为存在比较强的相关性。其中, $\gamma_{1}$ 为 0.6832 , 证明 郑州市物流业与国民生产总值之间存在着正相关性，物流业与区域经济的发展有着密切的关 联, 经济的不断发展推动者郑州物流枢纽的建立, 而物流枢纽的确定又能在一定程度上带来 枢纽经济效应。而在第一、第二、第三产业与货运周转量的对比中 $\gamma_{2}>\gamma_{3}>\gamma_{4}$ 根据排序可知, 对郑州市物流业来说, 第一产业对物流业发展有着重要的影响, 同时第二第三产业也有着密 切的关系。

对于第一产业， $\gamma_{2}$ 其相关性已达到 0.8197 ，郑州市在农业资源、尤其是在农业产业化经 营上有着较强的优势, 但从图 3 中可以看出, 近年来第一产业增速与物流发展相关性变弱。 $\gamma_{3}$ 和 $\gamma_{4}$ 中，作为老工业基地郑州，工业产业也对物流业发展产生了巨大的贡献，并且从图 3 中 可以看出, 工业增速与物流业增速在近年来呈现出来强相关性, 这跟郑州市的工业经济不断 优化、高质量发展有着密切的关系。 $\gamma_{4}$ 代表着第三产业与物流业的相关性最低, 郑州的三产 结构虽然在不断调整，但是仍缺乏大型电商、IT 技术及金融公司在郑落脚，因此发展较为缓 慢，对物流业没有起到应有的支撑作用。 


\section{4. 总结}

通过对郑州物流业与区域经济的灰色关联性分析，可以看出区域经济的发展对物流业有 着重大的推动作用, 因此, 为了发展郑州物流业, 郑州市应加强现代农业物流的运用, 优化 整合资源打造农产品供应链方向，持续做大做强农业产业化; 深化“中国制造2025”战略平台 对制造业转型发展要求, 以发展物流产业为契机, 通过延伸物流产业链带动制造产业转型升 级; 调整政策，吸引计算机、通信、电商、金融等更多大型企业在郑州落脚，加快第三产业 成为郑州经济新脊梁。

作为“中部崛起”的核心力量、中原城市群的核心城市，相信郑州在众多国家战略和机遇 下，产业一定会不断的优化和发展，但随着“打赢蓝天保卫战”以及推进运输结构调整政策的 相关要求, 郑州的物流业面临着前所未有的挑战, 资源整合形势严峻, 物流转型发展需求强 烈。对政府来说, 应不断优化政策体系, 积极克服物流业发展中遇到的如土地、税务等问题, 引导和支持现代物流业转型, 服务于区域经济发展; 对物流企业来说, 应不断探索和尝试新 的模式, 开展资源整合和共享, 坚持高效低耗可持续发展道路, 支持区域经济高质量发展, 并大力依托物流枢纽打造物流枢纽经济; 对产业方面, 应不断优化产业结构, 通过产业的不 断发展创造更多物流需求，形成物流业与区域经济相互支持和促进的积极态势。

\section{致谢}

本文为郑州市2019年度社会科学调研课题《郑州高质量建设国际冷链物流中心路径研究》 (ZSLX2019352)的阶段性成果之一。

\section{References}

[1] CHAI Xiaojie, YU Lijing, Quantitative Analysis of Synergy between Regional Logistics and Regional Economy-A Case Study of Yantai, Logistics Engineering and Management, pp. 32-34+24, 2017.

[2] LIU nan, LI Yan, Research on the Relationship between Modern Logistics and Economic Growth-An Empirical Analysis Based on Zhejiang Province. Journal of Industrial Engineering Management, pp. 151-154, 2007.

[3] TAN Qingmei, FENG Lingyun, GE Yun, Research on the Contribution of Logistics Capability to Regional Economy. Discussion on Modern Economy, pp.22-24,2003.

[4] GUO Hubin, DENG Zhituan, Study on the Coordinated Development of Regional Logistics and Regional Economy in the Yangtze River Economic Belt, Contemporary Economic Management, pp.41-48,2019.

[5] Zhengzhou Municipal Bureau of Statistics, Statistical Communiqué of Zhengzhou City's National Economic and Social Development in 2018.

[6] YU Guifang, Empirical Study on Logistics and Regional Economic Development in Zhuhai, Logistics Engineering and Management, pp.10-12,2019.

[7] FANG Yan, An Empirical Analysis of the Relationship between Logistics Industry and Economic Development in Heyuan , Market Forum, pp.64-66,2013. 